\title{
Evidence of strong hydrogen bonding in crystal structures of transition metal complexes
}

\author{
D.S. Kretić, D. Ž. Veljković, S. D. Zarić \\ ${ }^{1}$ Universitet of Belgrade - Faculty of Chemistry, Studentski trg 12-16, 11000 Belgrade \\ danijela@chem.bg.ac.rs
}

Hydrogen bonds are of greate importance for understanding of different processes in chemistry, crystalography and biology. [1] Properties of hydrogen bonds were subject of numerous experimental and theoretical studies. [1] Specially interesting case represent hydrogen bonds involving transition metal complexes since coordination of ligands can have significant influence on electrostatic potentials of coordinated molecules. [2] Here we present detailed analysis of crystalographic data combined with quantum chemical calculations of very strong hydrogen bonds between water and acetylacetonate ligand of different transition metal complexes.

Cambridge Structural Database (CSD) was searched for all structures containing O-H/O interactions between water molecule and acetylacetonato ligands of transition metal complexes. Geometrical parameters extracted from crystall structures were analyzed and compared with quantum chemical calculations performed on model systems. The O-H/O interactions were studied on model systems containing water and neutral or charged square-planar complexes of Ir, $\mathrm{Rh}, \mathrm{Pd}$, and Pt. The strongest interactions were found in charged model systems and these results are in agreement with the predominant electrostatic nature of hydrogen bond (-16.54 $\mathrm{kcal} / \mathrm{mol}$ ). However, suprisingly strong $\mathrm{O}-\mathrm{H} / \mathrm{O}$ interactions were identified also in neutral model systems. The calculated energies of these interactions are -7.98 and $-8.22 \mathrm{kcal} / \mathrm{mol}$ in $[\mathrm{M}(\mathrm{acac})(\mathrm{en})] / \mathrm{H} 2 \mathrm{O}(\mathrm{M}=\operatorname{Ir}(\mathrm{I}), \mathrm{Rh}(\mathrm{I}))$ model system, respectively.

Using geometrical cristeria for hydrogen bonds 82 structures with $220 \mathrm{O}-\mathrm{H} / \mathrm{O}$ contacts involving water molecule and coordinated acetylacetonato fragment were found. All extracted structures were statistically analyzed and results of analysis were in agreement with the results of quantum chemical calculations on model systems.

Although the metal is not directly involved in hydrogen bonding, the results of theoretical studies show that the nature of metal atom has significant influence on the strength of hydrogen bonds of ligands.

[1] T. Steiner, Angew. Chem. Int. Ed., 2002, 48-76.

[2] G. V. Janjić, M. D. Milosavljević, D. Ž. Veljković, S. D. Zarić, Phys. Chem. Chem. Phys, 2017, 8657-8660.

\section{Keywords: metal complexes; hydrogen bond; crystal structure}

This work was supported by the Serbian Ministry of Education, Science and Technological Development (Contract numbers:451-0368/2020-14/200168.) 